\title{
Prediction of fire loading on the structures using computational fluid dynamics
}

\author{
Romana Erdelyiová $^{1,}{ }^{*}$, Lucia Figuli $^{1}$ and Matúš Ivančo ${ }^{1}$ \\ ${ }^{1}$ University of Žilina, Faculty of Security Engineering, Univerzitná 8215/1, 01026 Žilina, Slovak \\ Republic
}

\begin{abstract}
The development of a fire in a large-space fire section differs significantly from the development in a small fire section. In large-space objects, to design structures under the fire load often proceeds through a performance-based approach. Advanced methods can be used in all parts of the design - in predicting of the scatter of temperature field, in calculating of the heat transfer to the structure and in assessing of the mechanical behaviour of the structure or its part under the fire load. The prediction of the gas temperature in the fire compartment is crucial for the structure design. The paper is focused on selection of different fire scenarios in the large-space building. The aim is to provide background for structural design in a fire using a performance-based design. The problem is solved by using FDS (Fire Dynamics Simulator) software based on the CFD (Computational Fluid Dynamics) method.
\end{abstract}

\section{Introduction}

Structures loaded by fire can be considered as accidental case of actions. To make a structural analysis of fire loaded structures is not such simple task as well as with all another accidental loads (blast [1,2], impact, and earthquake). Various aspects have to be considered. Firstly the fire load has to be analysed (prediction of the fire scenarios - heating rate, exposure temperature and time). Consequently as well as the structural response of the elements. Problems associated with fire resistance of steel and reinforced concrete columns exposed to fire on less than four sides (such as embedded in firewalls) were described in [3]. The recent research on timber-concrete composite (TCC) systems exposed to fire conditions are summarized in $[4,5]$. Complex fire protection design is focusing not only to structural response but to the design and testing of fire-resistant materials, as well as the development and application of post-fire assessment and repair strategies [6-8].

\section{Fire design analysis}

Generally in structural fire design analysis various logical steps are required. Fire load has to be set according to the selected relevant design fire scenarios, corresponding design fires has

\footnotetext{
*Corresponding author: romana.erdelyiova@ fbi.uniza.sk
} 
to be determined, temperature evolution with the structural members and the mechanical behaviour of the structure exposed to fire have to be calculated.

\subsection{Fire load}

Fire load depend on the characteristics of the fire. Fire in the closed space, inside of the building is determined by the space geometry, ventilation, sort and amount of the fuel. The fire behaves in various phases (see Fig.1). Initiation is a process caused by an exothermic reaction and is characterized by an elevated temperature, which is indicated to achieve maximum ambient conditions. Fire development, comes after the initiation. The fire grows as function of minimum fuel with minimal outdoor conditions. If there is a presence of adequate amount of fuel and oxide, fire arise its intensity influencing by the reaction of the substances on the fire. Flashover is the transition between the fire development and fully developed fire, where the burning of all flammable substances is expected. Fully developed fire, during this phase heat release obtain the maximal values and the resistance of the structures is very important. Burning out is the last phase, all flammable substances and the ability to heat release with the temperature is dropping down.

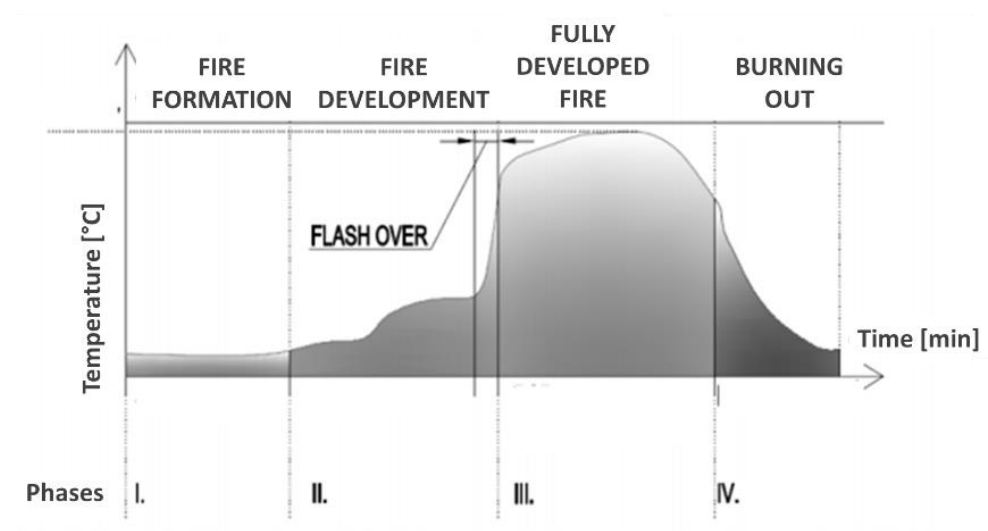

Fig. 1. Individual phases of fire.

In the field of fire scenario research, it is necessary to define the fire load in the space correctly. There are two types of fire load: permanent and accidental fire load. Permanent fire load depend on the material of structures, i.e. walls, floors, etc. Accidental fire load depend on the stored material, furniture, etc. placed inside of the structure.

\subsection{Temperature curves}

A design fire is considered in form of temperature-time curves. In the dynamics of combustion we recognize four basic types of nominal temperature curves. The curves determine the temperature of the gases in the fire-loaded area. The types of temperature-time curves are: normal temperature curve, external fire temperature curve, slow heating curve, hydrocarbon temperature curve [9]. The most used curve is normal temperature curve, expressing the cellulose burning (1), where the $\theta_{g}$, the temperature in the fire compartment is set:

$$
\theta_{g}=20+345 \log 10(8 t+1)
$$


In the following fire analysis the hydrocarbon temperature curve (2) expressing the burning of oil product will be used

$$
\theta_{g}=20+1080\left(1-0.355 e^{-0.167 t}-0.675 e^{-2.5 t}\right)
$$

Fig. 2 shows the standard and hydrocarbon temperature curves used to model the fire load of structures. The curves are plotted depending on the time.

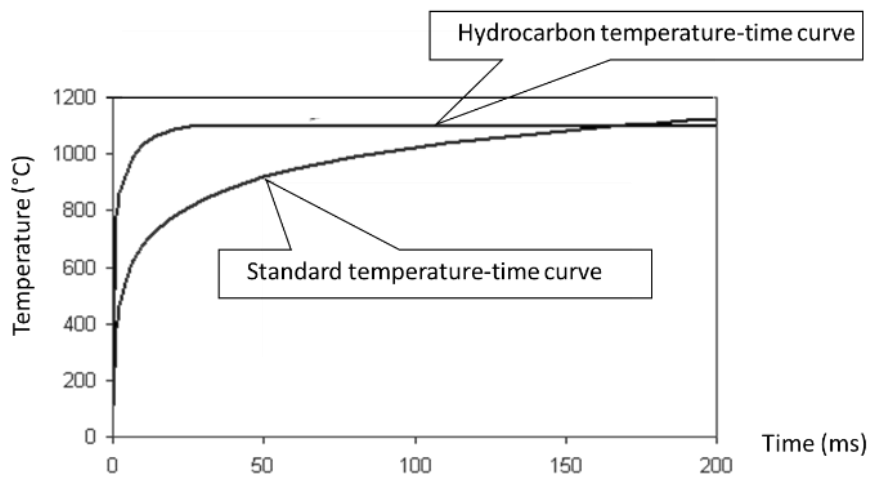

Fig. 2. Normative temperature-time curve.

\section{Structural fire design analysis of selected structure}

\subsection{Disposition}

As an analysed structure a hall was selected on the basis of research made through the international project Steel cladding systems for stabilization of steel buildings in fire (STABFI). The most used type of structure used in the countries involved in the project (Finland, the United Kingdom, Germany, Hungary and the Czech Republic) were selected (see Fig. 3). Length $41 \mathrm{~m}$, width $31 \mathrm{~m}$ and the structure height $10 \mathrm{~m}$. The steel structure is composed from the truss girders and pillars. Six modified warren truss girders with the height $3 \mathrm{~m}$ and 24 steel rolled pillars.
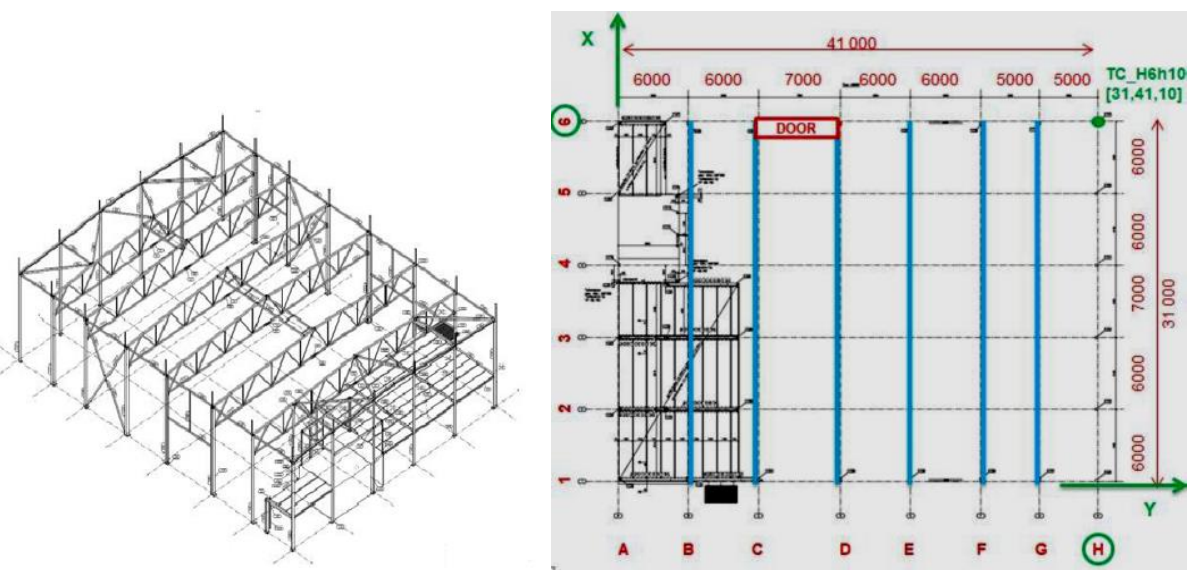

Fig. 3. Disposition of the analysed structure. 


\subsection{Numerical analysis of fire load propagation}

In mathematical modelling of fire and stability losses, it is important to use physical mechanisms of liquid transfer, heat transfer, stress and deformation analysis of compliant bodies and another physical effects which determine the accuracy of the solution. It is necessary to enter the correct input parameters: space geometry, fineness of computer network, materials used, space ventilation, combustion kinetics [10]. The fire model in the fire compartment enters several parameters: chemical composition of combustion products, wavelength, emissivity and others. The FDS model works by calculating the fraction, the number of radiation rays and the heat released by radiation. Structural fire design analysis of selected structure were made using a performance-based design. The problem was solved by using FDS (Fire Dynamics Simulator) software based on the CFD (Computational Fluid Dynamics) method. In the numerical analyses two fire scenarios were considered, based on the different venting space. Based on the simulation, we can observe the effect of venting on temperature development and gas propagation during the fire in the examined object.

\subsection{Fire scenarios}

As was just mentioned two fire scenarios, registered as scenario A and B, were considered. Fire scenario A is a basic fire scenario. The source of burning are wooden pallets with polyethylene terephthalate (PET) bottles, packed in cardboard boxes (simulation of packaging material). Pallets are placed two and three side by side with a geometry of $1 \mathrm{~m} \mathrm{x}$ $4 \mathrm{~m} \times 6 \mathrm{~m}$ for the possible passage of the manoeuvring technology (forklift). In the case of fire scenario A, we consider one pallet is burning, the others are simulated as noncombustible, creating obstacles to the flow of combustion products. The rate of the heat release per unit area (HRRPUA) used in the simulation is based on the 2002 NFPA experimental study [11].

Fire was simulated on the area of $1271 \mathrm{~m}^{2}$, where 35 racks are positioned 35 with the distances $5 \mathrm{~m}$ (Fig. 4). Source of the initialisation (point source of fire with the area of $1 \mathrm{~m}^{2}$ ) is a burner, simulating the burning of liquid substance (kerosene). The kerosene was selected because is highly used, in the plant operated in the hall, for the machine parts cleaning. Energy of burner is simulated using the ramp function (Table 1). In first $300 \mathrm{~s}$ of the burner capacity the energy of $900 \mathrm{~kW} / \mathrm{m}^{2}$ is released.

Table 1. Burner capacity in the software FDS.

\begin{tabular}{|c|c|c|c|c|}
\hline Time [s] & 0 & 100 & 300 & 600 \\
\hline Fraction & 0.0 & 1.0 & 1.0 & 0.0 \\
\hline
\end{tabular}

Assigning an excessive ignition temperature to each racks was necessary, based on an experimental study. The dependence of the released heat on the oxygen consumed in the space was verified experimentally. Reducing the amount of oxygen in the room, the combustion slows down and the combustion is completely stopped. The mesh is based on the analysis of the computer mesh sensitivity. The size of the computer mesh is $500 \mathrm{~mm} \mathrm{x}$ $500 \mathrm{~mm}$ x $500 \mathrm{~mm}$. 

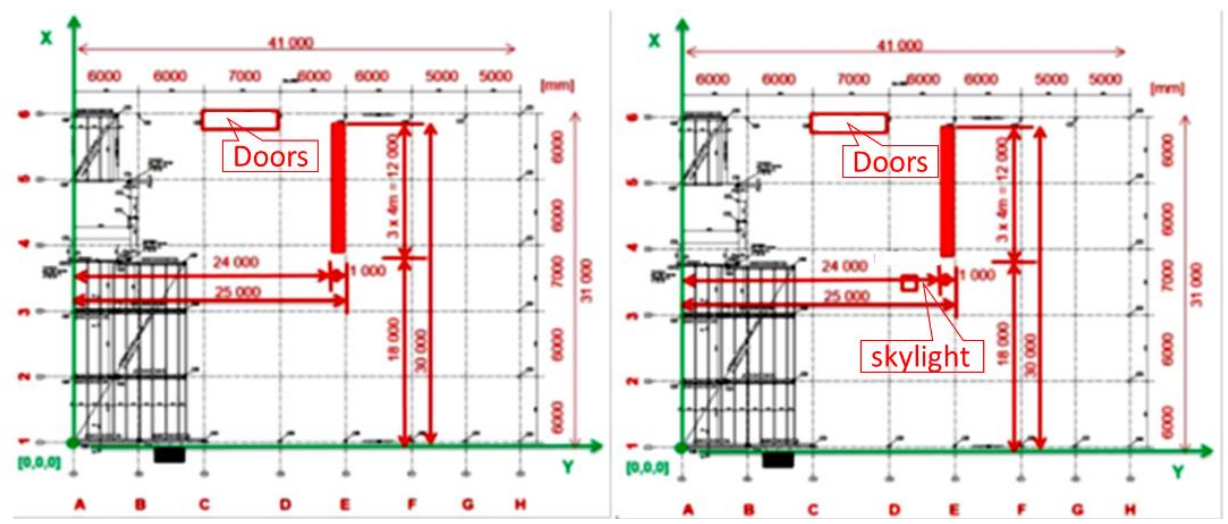

Fig. 4. Defined fire scenarios.

Fire scenario B is similar to the previous fire scenario A, but is complemented by a skylight with the dimensions of $1 \mathrm{~m} \mathrm{x} 1 \mathrm{~m}$. Changing the ventilation factors is possible to observe a large influence of ventilation on the development of fire, development of combustion products and other. In order to show the effects of a local fire in the examined area, ISO surfaces in different cutting planes were used. The section plane (Fig. 5) shows a characteristic temperature change based on a specific structural height. The maximum temperature in the tested object was measured for approximately 4 minutes of burning.
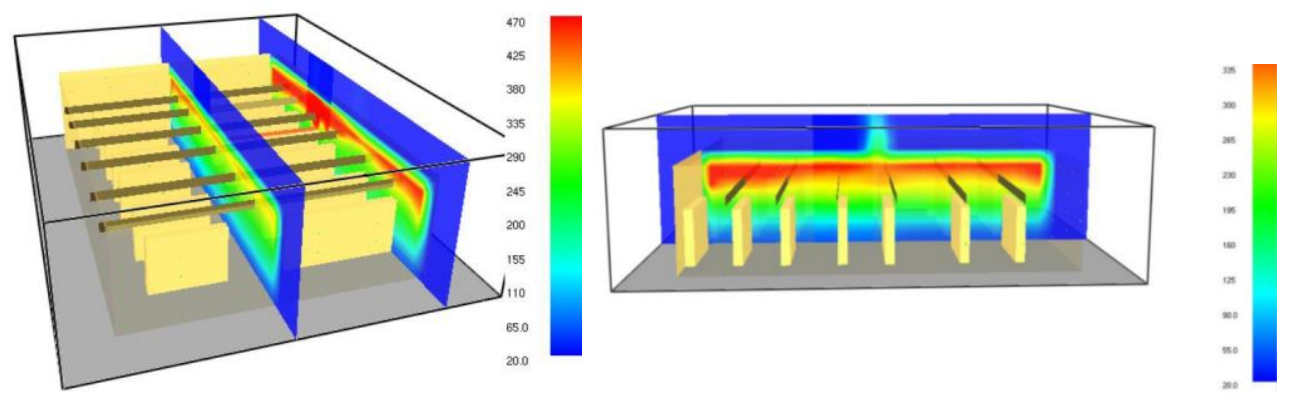

Fig. 5. Sectional view of fire scenario A and B at $250 \mathrm{~s}$ of fire.

In the vicinity of the simulated door opening, the temperature was much lower than that of the fire source, where the highest gas temperature values in the room were measured. The lowest measured value was reached by the corner of the room located furthest from the source of the fire. In fire scenario B, the vent hole in the roof structure was added as a skylight. The ISO area shows the discharge of the hot combustion gases during a fire through the skylight (Fig. 6). The maximum temperature in the test object was measured for approximately 4 minutes of burning.

The monitored parameter of the fire scenarios is the gas temperature distribution, measured with thermocouples installed in the surveyed object in several positions. Totally 153 sensors with material properties of Inconel 600 , a density of $8470 \mathrm{~kg} / \mathrm{m}^{3}$ and a specific heat capacity of $0.444 \mathrm{~kJ} /(\mathrm{kg} \cdot \mathrm{K})$ were simulated. Individual thermocouples in the source code are labelled based on their location. For example, the designation of the thermocouple H6h10 means that it is located in the ground plan H6 (by axis) at a height of $10 \mathrm{~m}$ above the floor. 

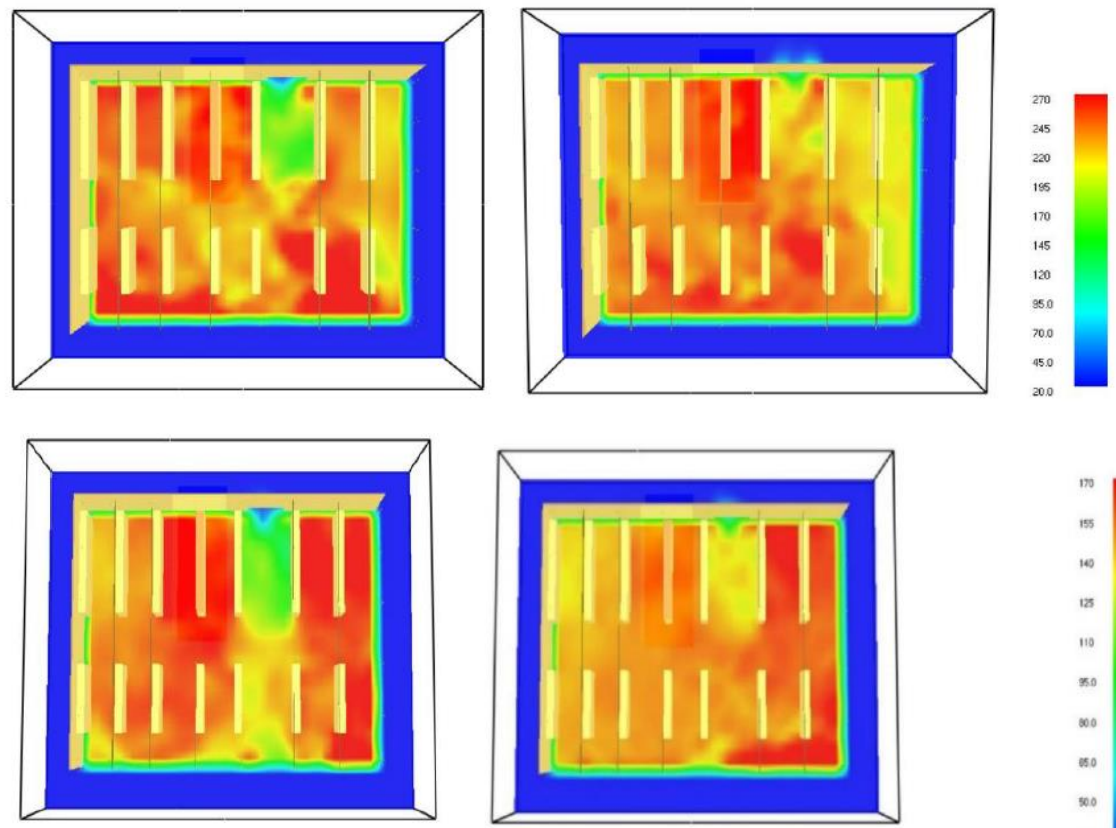

a)

b)

Fig. 6. Flowing of hot gases in the hall under and above of the floor a) Fire scenario A, b) Fire scenario B.

Flowing of cold air through the door from outside environment in the time of $525 \mathrm{~s}$ is demonstrated in Fig. 6 a). The suction of the cold air by upper opening of the door and fire conduction of the roof opening can be observed in the Fig. $6 \mathrm{~b}$ ).

\subsection{Comparison of fire scenarios}

The main objective of the studied issue and the construction of fire scenarios was to observe the impact of changes in ventilation conditions on the development and flow of hot gases in space.

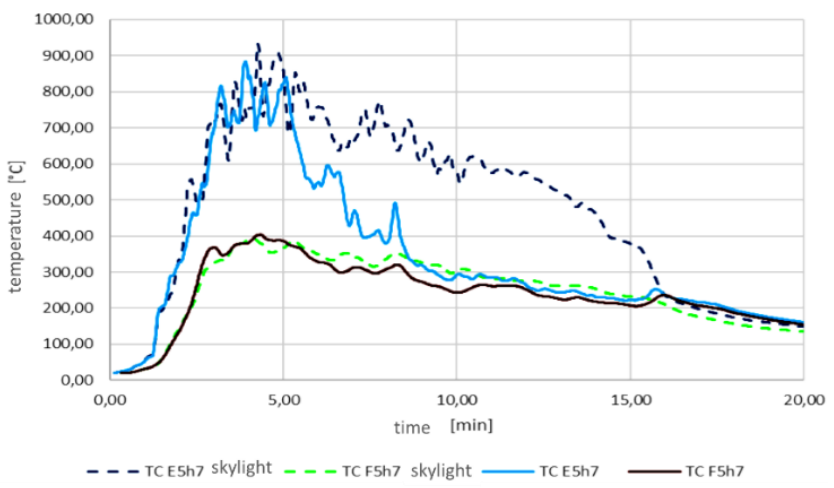

Fig. 7. Comparison of temperature time curves of fire scenario A and B. 
The measured temperature of the hot gases was slightly higher with fire scenario B with skylight added than in fire scenario A (Fig. 7). This is mainly due to sufficient oxygen access to the building, there is a more intense air flow, which supports the combustion itself in the building. From the fire point of view, it is recommended to install smoke barriers in the hall buildings, which prevent the accumulation of combustion products in the space and thus the continuous removal of heat and smoke. Higher air intake prolongs combustion in space. This can be observed in the case of fire scenario B, with a skylight, where high temperatures of hot gases are measured over a longer period of time.

Table 2. Comparison of results of fire scenario A and B.

\begin{tabular}{|c|c|c|c|c|c|c|}
\hline \multirow{2}{*}{$\begin{array}{c}\text { Sensor } \\
\mathbf{N}^{\circ}\end{array}$} & \multirow{2}{*}{ Position } & \multirow{2}{*}{$\begin{array}{c}\text { Maximal } \\
\text { reached } \\
\text { temperature } \\
{\left[{ }^{\circ} \mathrm{C} / \mathrm{min}\right]}\end{array}$} & \multicolumn{4}{|c|}{ Temperature $\left[{ }^{\circ} \mathrm{C}\right]$ in different duration of fire } \\
\hline & & & $5^{\text {th }} \min$ & $10^{\text {th }} \min$ & $15^{\text {th }} \min$ & $20^{\text {th }} \min$ \\
\hline E5h7 & $\begin{array}{l}\text { under the } \\
\text { fire skylight }\end{array}$ & $937.0 / 8$ & $903.0^{\circ}$ & 548.2 & 392.7 & 148.8 \\
\hline E5h7 & $\begin{array}{l}\text { under the } \\
\text { fire }\end{array}$ & $937.0 / 4$ & 880.2 & 315.6 & 222.9 & 170.0 \\
\hline F5h7 & $\begin{array}{l}6 \mathrm{~m} \text { from } \\
\text { the fire } \\
\text { skylight }\end{array}$ & $392.8 / 4$ & 372.0 & 302.5 & 231.3 & 134.8 \\
\hline F5h7 & $\begin{array}{l}\text { In the } \\
\text { vicinity of } \\
\text { fire }\end{array}$ & $399.0 / 4$ & 25.1 & 33.4 & 33.7 & 170.0 \\
\hline
\end{tabular}

While in the simulation of fire scenario A, high temperatures start to drop sharply as early as 5 minutes of burning. In some periods of combustion, the temperature difference between the two simulations is up to $400^{\circ} \mathrm{C}$, as seen in Table 2 .

\section{Conclusions}

The above-mentioned possibilities imply the importance of fire modelling and thermal stress of building structures, which is becoming an integral part of the design of structures, fire safety assessment of buildings, as well as of the area of protection of persons and property. The use of modern approaches and tools in the field of fire protection can help to prevent and prepare fire-fighting works more effectively.

The work was supported by the Internal Grant Scheme of Faculty of Security Engineering, University of Zilina from the grant No. 2019/10.

\section{References}

1. L. huli, Z. Zvaková, C. Bedon, Procedia Eng. 192 (2017)

2. L. Figuli, C. Bedon, Z. Zvaková, Š. Jangl, V. Kavický. Procedia Eng. 199 (2017)

3. W. Szymkuć, A. Glema, M. Malendowski. BiTP. 43, 3 (2016)

4. C. Bedon, M. Fragiacomo, Fire Technol 55, (2019)

5. T. Hozjan; C. Bedon; A. Ogrin, M. Cvetkovska, Journal of Structural Engineering, 145, 11 (2019)

6. L. Makovicka Osvaldova, J. R. Sotomayor Castellanos, Burning rate of selected hardwood tree species, Acta Facultatis Xylologiae Zvolen, 61, 2 (2019) 
7. P. Kadlicova, L. Makovicka Osvaldova, J. Jancik, M. Gaff, Effect of thermal and retarding treatment on flammability rate of tropical tree species, Wood research, 64, 1 (2019)

8. M. Gasparik, L. Makovicka Osvaldova, H. Cekovska, D. Potucek, Flammability characteristics of thermally modified oak wood treated with a fire retardant, BioResource, 12, 4 (2017)

9. ISO 834-11:2014 Fire resistance tests -- Elements of building construction (2019)

10. W. D. Walton, D. J. Carpenter, C. B. Wood. SFPE Handbook of Fire Protection Engineering (Springer New York 2016)

11. STABFI; Steel cladding systems for stabilization of steel buildings in fire (2020) 